\title{
Coastal seafloor observatory at Xiaoqushan in the East China Sea
}

\author{
XU HuiPing*, ZHANG YanWei, XU ChangWei, LI JianRu, LIU Ding, QIN RuFu, \\ LUO ShenQian \& FAN DaiDu
}

State Key Laboratory of Marine Geology, Tongji University, Shanghai 200092, China

Received January 21, 2011; accepted May 13, 2011

\begin{abstract}
The seafloor observation system is becoming an important infrastructure for marine research because it is transforming oceanic research from temporal investigation to long term observation. The East China Sea coastal seafloor observatory, located between $30^{\circ} 31^{\prime} 44^{\prime \prime} \mathrm{N}, 122^{\circ} 15^{\prime} 12^{\prime \prime} \mathrm{E}$ and $30^{\circ} 31^{\prime} 34^{\prime \prime} \mathrm{N}, 122^{\circ} 14^{\prime} 40^{\prime \prime} \mathrm{E}$, is constructed near the Xiaoqushan Island outside the Hangzhou Bay on the inner continental shelf of the East China Sea. The observatory is connected by a submarine optical fiber composite power cable that is more than one kilometer long and consists of a special junction box that transmits power and communication signals to different instruments. The special junction box has a variety of waterproof plugs and connects to three different instruments installed in a trawl preventer. The submarine optical fiber composite power cable is landed on the platform by The East China Sea Branch, State Oceanic Administration and the power is continuously supplied by the solar panels and solar battery on the top of the platform. The real time data are directly sent through the cable to the platform and are transmitted by CDMA wireless to the receiver at the State Key Laboratory of Marine Geology of Tongji University. Measurements at the observatory have been taken since April 20, 2009 after installation and the results have been interpreted. The characteristics of the near bottom boundary are constrained by a sediment suspension model using portion of the observed data. In particular, discussion is provided on the sea surface height anomaly at Xiaoqushan Island influenced by the tsunami driven by the 2010 Earthquake in Chile. The successful establishment of the coastal seafloor observatory is the first step toward future development of seafloor observation systems in China. It not only accumulates experiences in technology and engineering, but also paves the way for performing important oceanic research using the long term continuous observation platform.
\end{abstract}

seafloor observation system, the East China Sea, Xiaoqushan Coastal seafloor observatory, near bottom boundary layer, sea surface height anomaly

Citation: $\quad$ Xu H P, Zhang Y W, Xu C W, et al. Coastal seafloor observatory at Xiaoqushan in the East China Sea. Chinese Sci Bull, 2011, 56: 2839-2845, doi: $10.1007 / \mathrm{s} 11434-011-4620-\mathrm{y}$

Historically, ocean research is performed mainly from a vessel for a short period of time. With the development of remote sensing technology, we can explore the ocean on a large scale from space; but that technology is constrained to the sea surface and tells nothing about the undersurface water column or the bottom of the ocean. Earth and ocean scientists are on the threshold of a revolution enabled by the rapidly emerging technologies. We are expanding beyond short-term expeditions moving into a long-term seafloor observation. The most effective method is seafloor observa-

*Corresponding author (email: xuhuiping@tongji.edu.cn) tion network. It uses fiber-optical/power cables, which supplies power and collects data, to connect multi-discipline sensors on a large scale submarine network of remote, interactive natural laboratories for real-time, four-dimensional experiments on all weather conditions. The observational scopes not only cover the sea surface, but also water column and the seafloor. And the scientific research involves the integration of the physical, chemical, geological and biological oceanography [1].

The concepts and proposals for establishing seafloor observatories in North America and Europe have continued for more than ten years. The first step of the seafloor observation 
system started from series observatories near coastal and then developed to the ocean (www.neptune.washington. edu, www.neptunecanada.ca, marine.rutgers.edu/nurp/factech. html, www.mbari.org/mars) [2]. For example, The LEO-15 biological seafloor observatory was built in 1996 near New Jersey coastal which has 10 kilometers long cable and located at 15 meters water depth. It has been obtained a series breakthrough results at its first operation ten years [3]. The largest scale and the most advanced ocean observation program in the world is OOI (Oceans Observatories Initiatives) of the National Science Foundation of the United States (www.neptune.washington.edu). However, the NEPTUNECanada (North-East Pacific Time-series Undersea Network Experiments (Canada), www.neptunecanada.ca) is the largest network that is functional so far.

Comparing to the developed countries, China has only recently started to develop observatory technologies. The seafloor observation offers an opportunity to narrow the gap in oceanic research between China and the developed nations [4]. For the purpose of increasing the seafloor observation system, a project developing networking technology and application was founded in 2006 by Shanghai Science and Technology committee. It was to design the junction box and test information transport technique in the East China Sea near Shanghai to accumulate the seafloor observation experiences and to solve the technical bottleneck. Based on the science, technology and engineering investigation, the East China Sea seafloor experimental observatory was installed near Xiaoqushan Island and began to work on April 20, 2009. It is the first time and the first step in seafloor observation system test in China. Here in this paper, we try to introduce the observatory technical preferences and the primary interpretation of the data collected so far.

\section{Xiaoqushan seafloor observatory}

The Xiaoqushan Seafloor Observatory is located near the
Xiaoqushan Island between $30^{\circ} 31^{\prime} 44^{\prime \prime} \mathrm{N}, 122^{\circ} 15^{\prime} 12^{\prime \prime} \mathrm{E}$ and $30^{\circ} 31^{\prime} 34^{\prime \prime} \mathrm{N}, 122^{\circ} 14^{\prime} 40^{\prime \prime} \mathrm{E}$, which is $20 \mathrm{~km}$ distance from Yanshan international harbor (Figure 1a). The average water depth in this area is $15 \mathrm{~m}$. The XEO belongs to an unregular semidiurnal tide area, which is not far from the deep waterway. In this area the sedimental material is medium to fine sand and the water is highly turbid because of its close proximity to one of the Yangtze River's transportation Channels characterized by mud and sand. It is a vital ecosystem because it is the fishing eel area.

The observatory consists of a submarine optical fiber composite power cable that is more than one kilometer and a special junction box, which provides the power and communication signals to different instruments. The special junction box, which has three different kinds of waterproof plugs, is installed in a trawl preventer and connects to three different instruments, CTD, OBS and ADCP, separately. The submarine optical fiber composite power cable is landed on the platform by The East China Sea Branch, State Oceanic Administration of the People's Republic of China (Figure 1a), and the power is continuously supplied by the solar panels and solar battery on top of the platform. The real time data are directly sent through the cable to the platform and are transmitted by wireless CDMA to the receiver at the State Key Laboratory of Marine Geology of Tongji University. The installation technologies are designed during the construction of the observatory. An informational system is established as well to receive, monitor, and manage incoming data.

Continuous measurements at the observatory started on April 26, 2009, which include a turbidity sensor (OBS) and a $1200 \mathrm{kHz}$ ADCP on an SBE-16 CTD system that was installed in a standstill trawl preventer standing about $80 \mathrm{~cm}$ above sea bottom. The observational data are continuously transmitted through the junction and the fiber-optical cables to the platform and then sent to the receiver located at the State Key Laboratory of Marine Geology in Tongji University. For the first five months the sampling rate of ADCP
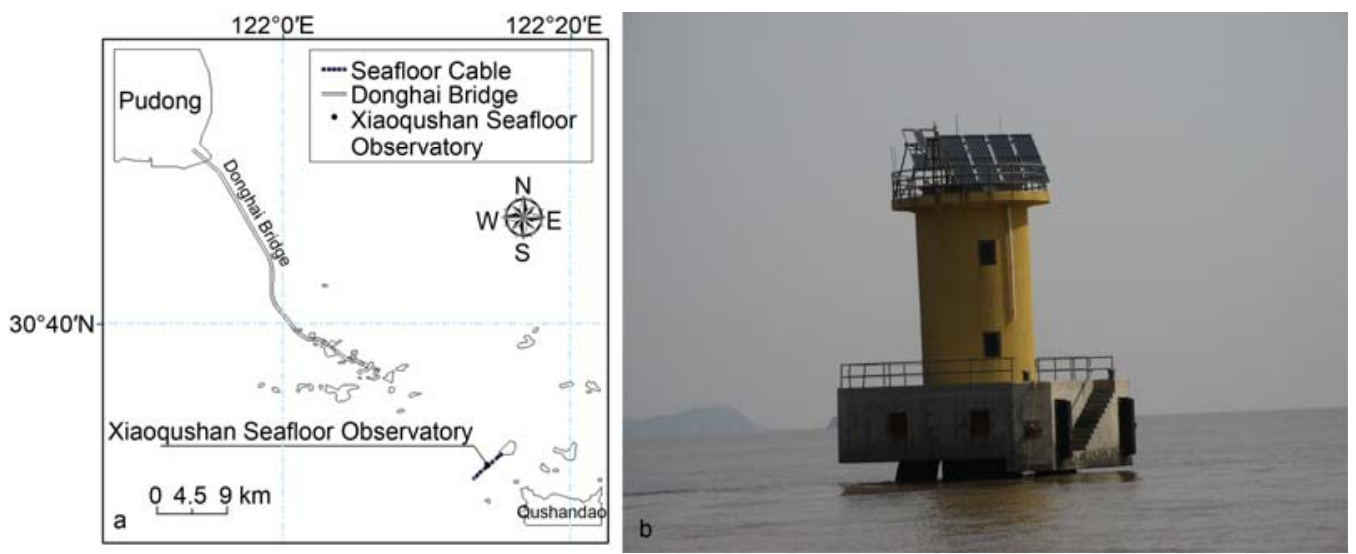

Figure 1 a, The location of Xiaoqushan Seafloor Observatory; b, the observatory landing platform. 
was 1 time per minute, and the spatial resolution was $25 \mathrm{~cm}$. The CTD was about 1 time per minute. From October 13, 2009, the frequency of data transmission of the ADCP and CTD was shifted to $15 \mathrm{~s}$. The information received at Tongji University includes near bottom temperature, conductivity, pressure, turbidity, the current values and directions of every $25 \mathrm{~cm}$ layer from $80 \mathrm{~cm}$ above sea bottom to the sea surface, and status parameters of all equipment.

\section{Components of key technologies}

\subsection{Special junction box}

Seafloor observation network connects different types interface equipments by cables and wireless communications. Because the individual observation sensors need different types of power supplies, the main power at the station needs to be divided and delivered via the cable to the undersea nodes. Information collected by every sensor is transmitted to the shore station or data center and the commands will be sent from the shore station or controlling center to change every sensor or equipment's working model. The signal transmission and the power conversion are accomplished by the junction box [5].

The main function of the junction box is to fulfill the power conversion and supply, the data collection, coding and transmission. It realizes the remote controlling and management to all equipment. Sometimes it can be used to add miscellaneous functions such as wireless communication for the underwater mobile platform. And it even can be used for AUV (Autonomous Underwater Vehicle) power docking. In the junction box, the power module for power conversion and allocation, the instruments data collecting and coding module and the electrical-optical transform module were designed for three kinds of instruments. There are one interface for 10-48 V direct current input and four interfaces for 12-24 V direct current output, which can supply $10 \mathrm{~W}$ for each. Several interfaces, such as RS-232 and RS-485, by the I2C bus extender was designed at the same time. The data collecting, coding and transmission were made by programmable controller on the control panel. All the special design was for Coastal seafloor observatory of the East China Sea near Xiaoqushan special junction box.

\subsection{Data acquisition and integration}

Seafloor observation network remotely monitors continuous, real time and long term interactions among physical, chemical, biological and geological phenomena under any weather conditions. The observation scales include the solid earth under seafloor, the sea bottom, the water column, the sea surface and the atmosphere above. The data set is huge and the information inside is enormous. Coastal seafloor observatory of the East China Sea near Xiaoqushan has only three sensors, but the data received at terminal everyday is over $30 \mathrm{Mb}$. For tens of instruments or more, multidiscipline and multi observation parameters, add real video data, the data set of whole system will be over a gigabyte. Such huge data need a high performance computer with rapid data processing capabilities and the data center will include real-time reception, quality control, storage, analysis and mining, and sharing and applications of data. The successful example is Cyberinfrastructure Program of American National Science Foundation (National Science Foundation Cyberinfrastructure Council, 2007) [6]. It needs to set up a hardware environment including high capacity, distributed data storage, high performance computer, wide band internet instruments and high performance visualization equipment and a series of software packaging.

For the purpose of testing the data acquirement and integration and applications, a seafloor observation system visualization information system was designed for the Xiaoqushan Seafloor Observatory. The information system is based on the data flow, applications flow and user oriented to make a top-level design. The "NET" development platform and C\# language were used. The ArcGIS toolkit and object-oriented data model was also used. In order to achieve the advancement and practicability, the new OpenGL extention functions and advanced color laguage was used to program for the GPU (Graphics Processing Unit) to realize three-dimensional visualization application model. The information system and database were made according to computer software and database criteria to assure the information system's openness and the database sharing. In addition, the safety, the reliability, the stability and the friendly user interface of the information system were considered.

The architecture of seafloor observation system visualization information system consists of the information flow from the data acquirement, organization, management and sharing to modeling and visualization applications. It consists of a complete information processing link. The information system can be divided into four functional modules. The first one is data receiving module, which fulfills the data reception, decoding, storage in bata-base and management. The second module is for information control, which is for instrumental status control and data quality control. The third module is two dimensional GIS, which finishes GIS functions like the metadata management for the observation data, the query and statistical analysis and so on. The last one is a two or three dimensional linkage module, which primary fulfills two- or three-dimensional model for visualization applications. All the modules are designed according to "NET", a standard component that can be run separately but also can be nested with each other. In addition, all the modules can be connected seamlessly with SQL SERVER 2005 database system to perform highly effective database operations. The information infrastructure can finish all the tasks for the Xiaoqushan Seafloor Observatory (Figure 2). 


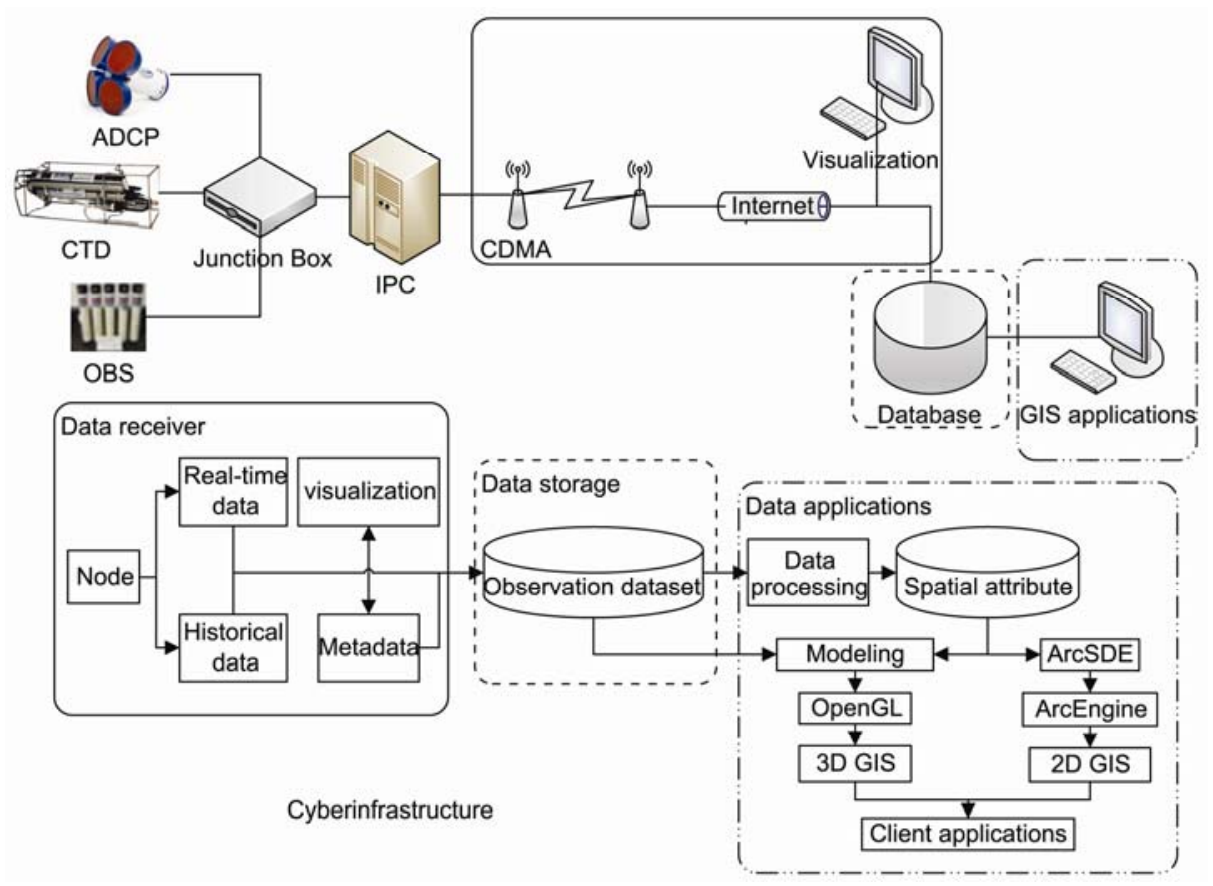

Figure 2 The seafloor observation system visualization information system.

\section{Initial analyses of in situ observations at the Xiaoqushan seafloor observatory}

\subsection{Data description}

Since its successful establishment in April 2009, the Xiaoqushan Seafloor Observatory have been transmitting data at up to $30 \mathrm{Mb}$ every day. Data obtained during the first $40 \mathrm{~d}$ are shown in Figure 3. The wind was at a relatively steady state with an average speed of $6.3 \mathrm{~m} / \mathrm{s}$, and blew northward and southward alternately. For example, from the end of April to 3 May, the average wind speed was $9.5 \mathrm{~m} / \mathrm{s}$ and the direction was around 10 degrees north by east (Figure 3a). Both of the sea surface temperature (SST) and temperature near the bottom rose gradually from $16^{\circ} \mathrm{C}$ to $21^{\circ} \mathrm{C}$ when summer was approached (Figure $3 \mathrm{~b}$ ). The trends of SST and near bottom water temperature were comparable and their discrepancy was less than $1{ }^{\circ} \mathrm{C}$, suggesting the water column was well mixed. The sea level variations of spring-neap tides as well as the daily high-low tides can be seen from the time series of depth variation (Figure 3c), indicating the local tidal type is a mixed semidiurnal tide dominated by semidiurnal signals. The daily tidal range varied due to unequality of mixed semidiurnal tide, which is characterized by distinction among higher high tide, lower low tide, lower high tide and higher low tide. The largest tide range was $3.5 \mathrm{~m}$ during spring neap and the smallest tide range was $1.5 \mathrm{~m}$ observed during neap tide. According to the time series of near bottom current velocity shown in Figure $3 \mathrm{~d}$, it is notable that the southnorth current velocity was about 2.5 times stronger than the east-west current velocity. Moreover, the current velocity during spring tide was faster than that during neap tide. Current flew southward during flood tide and the speed varied smoothly. However, the current direction during ebb tide shifted abruptly with a northward trend.

\subsection{Hydrologic processes near the bottom boundary}

One of the objectives of the East China Sea bottom observatory is to explore the coastal transportation of sediment and sand which is supplied by the Yangtze River. These sediments experienced complex processes such as suspension, deposition and resuspension on the broad and shallow shelf [7]. The hydrological variation due to the tidal inequality played an important role in controlling the distribution and transportation of sediments [8]. The echo intensity obtained by acoustic Doppler current profiler (ADCP) revealed information about the concentration of suspended sediment in sea water [9], because echo intensity would be strengthened where more suspended sediments were founded. The distribution of echo intensity demonstrated that the nearer the bottom the larger the values were (Figure 4). The maxima of echo intensity with value of $220 \mathrm{~dB}$ appeared at $1 \mathrm{~m}$ above the bottom that formed a thin near-bottom-boundary layer which varied during the tide periods. The thickness of this layer reached as thick as $2 \mathrm{~m}$ during the spring tide and became thinner during neap tide. In this case, we can conclude that hydrological processes in different tidal periods induced varied shear stresses, which resulted in different processes of sediments. Larger shear stress at near bottom boundary drives more active sediment transportation. Drag coefficient $(\mathrm{Cd})$ was crucial to calculate shear stress. Based on present sediment model $[10,11]$, drag coefficient and 

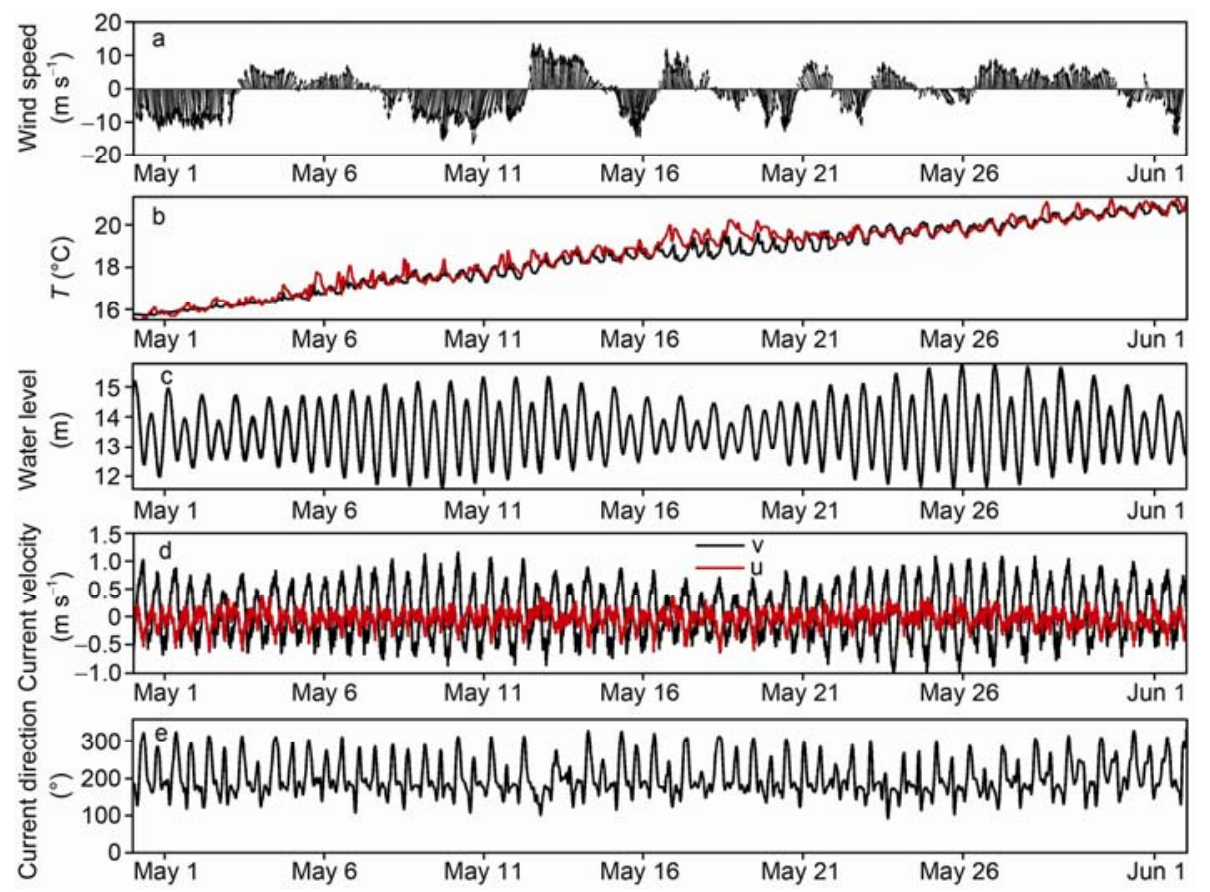

Figure 3 Data obtained during the first $40 \mathrm{~d}$ in 2009. a, Wind; b, sea water temperature, the black line shows the temperature obtained by CTD near the bottom, and the red line represents sea surface temperature obtained from the weather station 1 km away from Xiaoqushan Seafloor Observatory; c, water level; $\mathrm{d}$, current velocity obtained $1 \mathrm{~m}$ above the bottom, the black line is for south-north current $(v)$ and the red line is for the east-west current $(u)$; e, current direction for the current shown in $\mathrm{d}$.

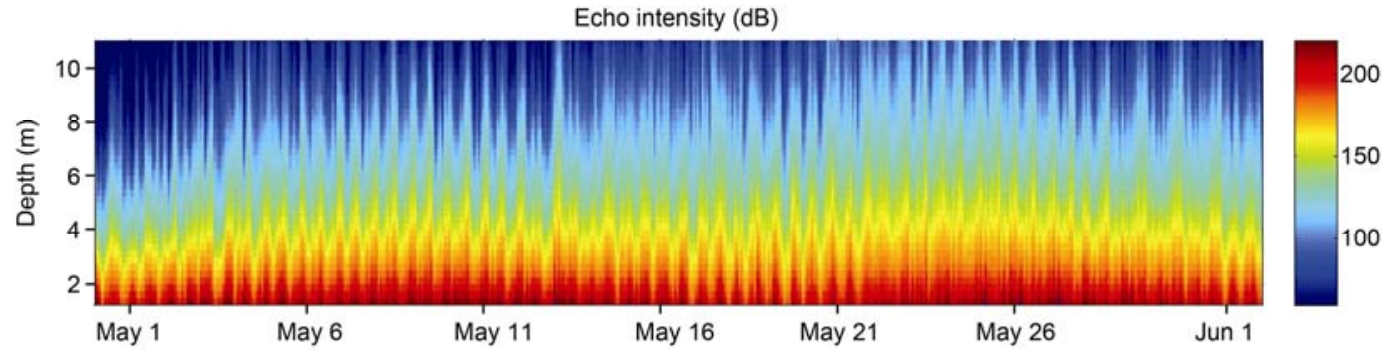

Figure 4 Echo intensity measured by ADCP in 2009 at the Xiaoqushan Seafloor Observatory.

shear stress as well as sediment transportation rate were calculated from ADCP and CTD measurements. The results (Figure 5) documented flood, ebb, spring and neap tide periodic variations, which were helpful for studying long-term sediment transportation.

The calculated drag coefficient values were in the range of $2.8 \times 10^{-3}-3.6 \times 10^{-3}$, and the mean value in neap tide was larger than that in spring tide. However, drag coefficient in neap tide was not necessarily always larger than that in spring tide considering the period of neap-tide 2 shown in Figure $5 \mathrm{~b}$ was of relatively smaller drag coefficient than spring-tide. Since the near-bottom shear and stratification accounted for the parameterization of drag coefficient, and strong shear variance and weak stratification due to resuspension intermittently occurred when current was weak during neap tide which was the possible reason for different variations during neap tide [11]. The shear stress near bottom boundary layer (Figure $5 \mathrm{c}$ ) varied little with the hourly- averaged value changed from 0.5 to $3.0 \mathrm{~N} \mathrm{~m}^{-2}$ and dailyaveraged value changed from 0.8 to $1.5 \mathrm{~N} \mathrm{~m}^{-2}$. The transportation rate (Figure $5 \mathrm{~d}$ ) varied with the same trend as shear stress and also exhibited spring-neap tide period with the mean value of $7.0 \times 10^{-3} \mathrm{~kg} \mathrm{~m}^{-2} \mathrm{~s}^{-1}$ during spring tide, which was $40 \%$ larger than the value of $5.0 \times 10^{-3} \mathrm{~kg} \mathrm{~m}^{-2} \mathrm{~s}^{-1}$ during neap tide. Furthermore, the notable daily cycle can also be distinguished from the time series of drag coefficient, near-bottom-boundary stress and the sediment transportation rate. Drag coefficient sustained large values of $3.3 \times 10^{-3}-3.5 \times 10^{-3}$ during ebb tide and decreased first and then increased during flood tide. To the contrast, transportation rate value rose from $2.0 \times 10^{-3} \mathrm{~kg} \mathrm{~m}^{-2} \mathrm{~s}^{-1}$ up to $15.0 \times$ $10^{-3} \mathrm{~kg} \mathrm{~m}^{-2} \mathrm{~s}^{-1}$ and then decreased again during ebb tide and it remained low during flood tide. This method of calculating near bottom boundary layer parameters demonstrates the potential usage of the data obtained from Xiaoqushan Seafloor Observatory for the detailed study of the 

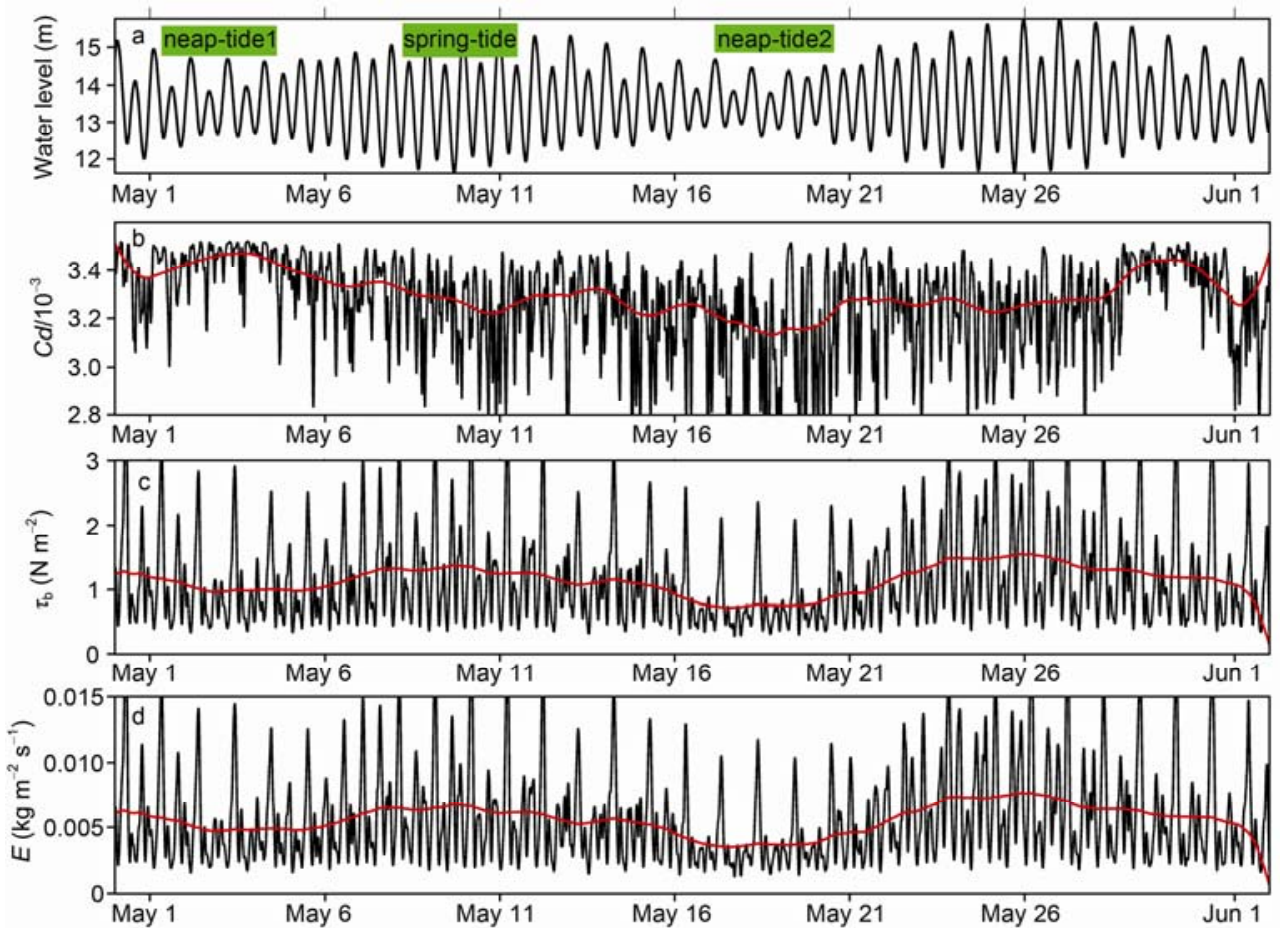

Figure 5 a, Sea level obtained by CTD; b, drag coefficient (Cd); c, near bottom boundary shear stress; d, sediment transportation rate. The three green shades in a represent two neap tides and one spring tide; black lines in b, c and d stand for hourly averaged data and the red lines for daily averaged data.
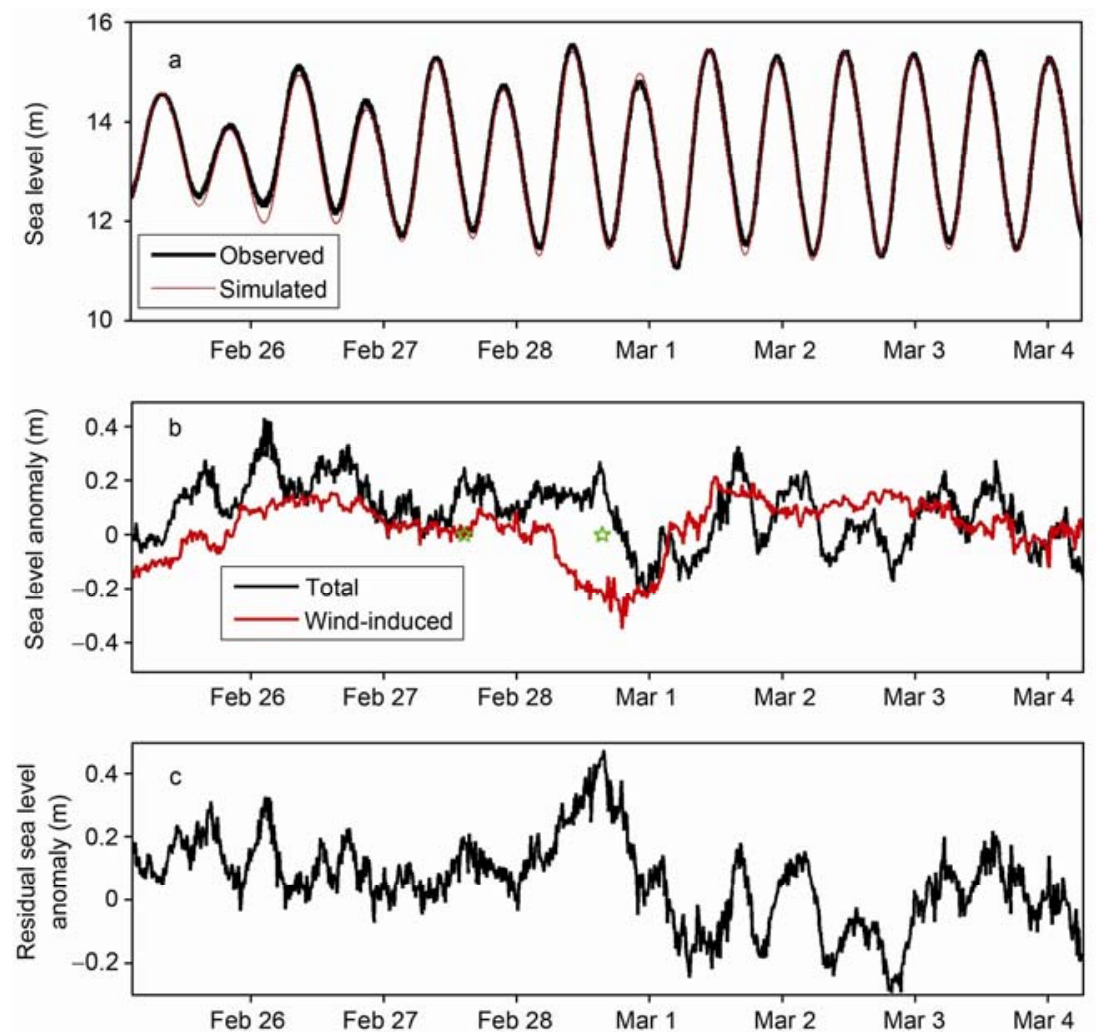

Figure 6 Sea level and its anomalies from Feb. 25 to Mar. 4 in 2010. a, Sea level time series, the black and thick line stands for the observed data and the red thin line for the simulated results; $b$, sea level anomaly, the black line shows the total anomaly by subtracting simulated tide signal from the observed data and the red line shows the sea level triggered by surface wind. The first green pentagram shows the time when Chile earthquake occurred and the second one for the time when tsunami reached Xiaoqushan; c, residual sea level anomaly, the total anomaly substracted the wind-induced signal. 
coastal sediment distribution and transportation in future.

\subsection{Sea level anomaly induced by the earthquake in Chile}

In situ measurements at the Xiaoqushan Seafloor Observatory not only can be used to monitor physical and sedimentary processes such as variation in turbidity and deposition rate in Yangtze River and the East China Sea (ECS) shelf, but also can be used to study responses of ocean environment and ecosystem to extreme weather/climate as well as earthquake and tsunami. The real-time series of sea level data obtained from CTD at Xiaoqushan Seafloor Observatory is used to learn how tsunami in remote regions may impact the coastal processes off the ECS. The tsunami, for example, induced by the 2010 Chile earthquake occurred off the coast of the Maule Region of Chile at 14:43 on Feb. 27 in 2010 (Beijing time, the first green pentagram labeled in Figure 6b) rating a magnitude of 8.8 on the moment magnitude scale, affected most of the Pacific ocean region $[12,13]$. According to the seismic wave propagation, $\mathrm{P}$-wave and S-wave arrived at Xiaoqushan Seafloor Observatory 20 and $27 \mathrm{~h}$ later, respectively. And the tsunami reached Xiaoqushan around $24 \mathrm{~h}$ forecasted by NOAA [12]. In order to get the actual time when tsunami arrived at Xiaoqushan Seafloor Observatory, the sea level variation due to tides (Figure 6a) simulated by harmonic analysis was subtracted from the observed CTD depth data yielding the total sea level anomaly (Figure 6b) and then subtracted the sea level change triggered by wind resulting in the residual sea level anomaly (Figure 6c). The maximal residual sea level anomaly $0.48 \mathrm{~m}$ appeared at 15:00 on Feb. 28 (shown by the second green pentagram in Figure 6b), which was consistent with the estimate from NOAA.

In summary, the two examples introduced above demonstrate the advantage of the sea floor observatory, which can obtain real-time and long-term measurements for comprehensive studies of the mechanisms of the oceanic dynamics and environmental variations under different weather conditions in the future.

The Xiaoqushan Seafloor Observatory and this paper cannot be completed without the blueprint and constructive comments from Pinxian Wang, who is in charge of the program. We also appreciate the help from East China Sea Bureau of State Oceanic Administration for providing the observation platform at sea and Donghua University for offering devices for solar power and wireless transmission. Thanks are also due to Kang Ding from University of Minnesota, Jian Lin from WHOI, Christopher R. Barnes from Canada NEPTUNE, Jiaxue Wu from Zhongshan University, Zengdi Pan, Enzhu Jiang, Maoxun Gong and Tongjun Li from East China Sea Bureau of State Oceanic Administration, and many other colleagues and students in the School of Ocean and Earth Sciences at Tongji University for their advice and help during the construction of the Xiaoqushan Seafloor Observatory. Special thanks to Professor Chuanlun Zhang from University of Georgia, who helpsus to revise the English version of this paper.

1 Favali P, Beranzoli L. Seafloor observatory science: A review. Ann Geophys, 2006, 49: 515-567

2 State Key Laboratory of Marine Geology. International Seafloor Observation System Report (in Chinese), 2006

3 Glenn S M, Schofield O M, Chant R, et al. The LEO-15 Coastal Cabled Observatory - Phase II for the Next Evolutionary Decade of Oceanography. SSC06 - Scientific Submarine Cable, 2006, 1-6

4 Wang P X. Seaflooor observatories: The third platform for earth system observation (in Chinese). Chin J Nat, 2007, 29: 125-130

5 Chen Y, Yang C J, Tao C H. Seafloor Observation System. Beijing: Ocean Press, 2006

6 National Science Foundation Cyberinfrastructure Council, Cyberinfrastructure Vision for 21st Century Discovery, 2007, 1-64

7 Gao S, Cheng P, Wang Y P, et al. Characteristics of suspended sediment concentrations over the areas adjacent to the Changjiang River estuary, the summer of 1998. Marine Sci Bull, 2000, 2: 14-24

8 Lozovatsky I, Liu Z Y, Wei H, et al. Tides and mixing in the northwestern East China Sea Part I: Rotating and reversing tidal flows. Cont Shelf Res, 2008, 28: 318-337

9 Cheng P, Gao S. Suspended sediment concentration measurements With ADCP: Feasibility analysis and in situ calibration (in Chinese). Oceanol Limnol Sin, 2001, 32: 168-176

10 Wang X H. Tidal-induced sediment resuspension and the bottom boundary layer in an idealized estuary with a muddy bed. J Phys Oceanogr, 2002, 32: 3113-3130

11 Werner S R, Beardsley R C, Lentz S J, et al. Observations and modeling of the tidal bottom boundary layer on the southern flank of Georges Bank. J Geophys Res, 2003, 108: 8005, doi:10.1029/2001JC 001271

12 Carayannis G P. The earthquake and tsunami of 27 February 2010 in Chile-Evaluation of source mechanism and of near and far-field tsunami effects. Sci Tsunami Hazards, 2010, 29: 96-126

13 Yu F J, Yuan Y, Zhao L D, et al. Evaluation of potential hazards from teletsunami in China: Tidal observations of a teletsunami generated by the Chile $8.8 M_{\mathrm{w}}$ earthquake. Chinese Sci Bull, 2011, 56: 1108-1116, doi: 10.1007/s11434-010-4307-9

Open Access This article is distributed under the terms of the Creative Commons Attribution License which permits any use, distribution, and reproduction in any medium, provided the original author(s) and source are credited. 